\title{
ARTRITE PRORIÁTICA COM MANIFESTAÇÃO NAS ATM: RELATO DE CASO
}

Nathan Dyoji NARAZAKI, Priscila BRENNERE, Paulo Afonso CUNALI

A artrite psoriática é definida como uma artrite erosiva crônica recorrente soronegativa de etiologia desconhecida em pacientes com psoríase cutânea, acometendo de 5 a $20 \%$ destes pacientes. A doença tem um caráter progressivo e normalmente acomete as articulações simetricamente, causando dor e limitação de movimento. A doença é de difícil diagnóstico e a manifestação na ATM é considerada rara. Este trabalho objetiva discutir a relação da artrite psoriática com manifestação da ATM por meio do relato de um caso clínico. Paciente gênero feminino, 35 anos, com limitação da função mandibular, medicada por médico Reumatologista. Foram utilizados placa oclusal de estabilização e exercícios mandibulares para tratamento, além de 2 injeções intra-articulares de hialuronato de sódio associada com corticóide no prazo de 4 meses. Concluí-se que o emprego de placas oclusais e exercícios mandibulares, junto com infiltrações intraarticulares podem ser eficientes no controle dos sintomas da artrite psoriática nas ATM.

Palavras-chaves: Articulação Temporomandibular; Artrite Psoriásica; Psoríase. 